\title{
Nodular Fasciitis of the Periorbital Area
}

\author{
Yoon-Jae Lee ${ }^{1}$, \\ Sue-Min Kim ${ }^{1}$, \\ Jung-Ho Lee ${ }^{1}$, \\ Young-Joon Jun', \\ Young-Jin Kim ${ }^{1}$, \\ Jeana Kim ${ }^{2}$
}

Departments of ${ }^{1}$ Plastic and Reconstructive Surgery and ${ }^{2}$ Pathology, Bucheon St. Mary's Hospital, The Catholic University of Korea College of Medicine, Bucheon, Korea

No potential conflict of interest relevant to this article was reported.
Nodular fasciitis is a reactive, non-neoplastic lesion that is most commonly found in the subcutaneous or superficial fascia of the extremities and trunk. Head and neck lesions are relatively uncommon and reports vary from $7 \%$ to $15 \%$ depending on the authors. Nodular fasciitis grows quickly, and shows a pleomorphic spindle cell pattern with increased mitotic activity. Such factors lead to cases where the lesion is mistaken for a malignancy such as fibrosarcoma and the case may end up with unnecessarily aggressive treatments. The intent of this paper is to report a relatively rare case of nodular fasciitis occurring in the periorbital area and also to highlight the importance of accurate diagnosis and non-aggressive management of this benign lesion.

Keywords: Nodular fasciitis / Pseudosacrcoma / Soft tissue tumor

\section{INTRODUCTION}

Nodular fasciitis is a self-limiting, non-neoplastic, reactive proliferation of connective tissue involving the subcutaneous or superficial fascia [1]. It can appear in any anatomic region but is most commonly found in the extremities or the trunk [1]. Nodular fasciitis is relatively uncommon in the head and neck lesions and many authors report a prevalence of about 7\% to $15 \%$ [2-6]. Nodular fasciitis is often mistaken as a sarcomatous lesion due to its rapid growth, rich cellularity, high mitotic activity and poorly circumscribed nature [5]. These malignant-like characteristics may lead to inappropriate, aggressive treatment which may cause psychological and physical morbidity to a patient. Therefore, we should be aware of the clinical and pathologic character of nodular fasciitis and should make accurate diagnosis prior to treatment.

\section{Correspondence: Young-Jin Kim}

Department of Plastic and Reconstructive Surgery, Bucheon St. Mary's Hospital, The Catholic University of Korea, 327 Sosa-ro 327beon-gil, Wonmi-gu, Bucheon 420-717, Korea

E-mail: psyjkim@catholic.ac.kr

Received October 24, 2013 / Revised February 13, 2014 / Accepted February 22, 2014

\section{CASE REPORT}

A 35-year-old man presented a mass at the medial side of the right upper eyelid (Fig. 1). It was found incidentally approximately three months prior. Since then the lesion grew rapidly and the patient was referred to our department to exclude the possibility of a softtissue malignancy. On physical examination, a mass of approximately $2.0 \mathrm{~cm}$ in size with firm and non-tender nature was noted. Paresthesia was noted over the forehead and scalp region of the supratrochlear nerve. Mechanical ptosis of the right upper eyelid was observed, but without any other abnormal findings on the general ocular examination. On computed tomography, a well demarcated $2.0 \mathrm{~cm}$-sized, contrast-enhanced subcutaneous mass of the right supraorbital area was detected with no adjacent bony destruction (Fig. 2). Before the excision, punch biopsy was performed and nodular fasciitis was confirmed. A complete excision was performed under general anesthesia and the defect was closed primarily by local flap coverage. Macroscopically, the tumor was $1.5 \times 1.8 \times 1.5 \mathrm{~cm}$ in size and was well circumscribed, non-encapsulated with rubbery to myxoid texture (Fig. 3). The histological results showed the nodular proliferation of plump and spindled fibroblasts arranged in long fascicles with whorled appearance (Fig. 
4). Frequent mitiotic figures were observed with scattered lymphocytes and extravasated red blood cells. Immunohistochemical study was performed, and the lesion stained positive for vimentin and smooth muscle actin but negative for cytokeratin, S-100 protein, desmin, and CD34 (Fig. 5). The patient underwent close observation and the resolution of the mass left only minimal scarring on the right periorbital area. The preoperative symptoms of mechanical ptosis and paresthesia over the forehead and scalp area subsided (Fig. 6). The postoperative follow-up was main-

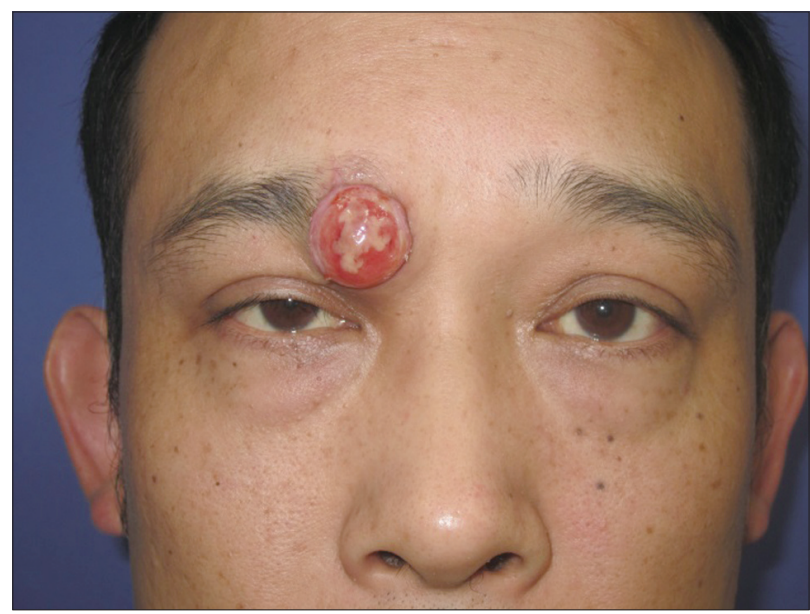

Fig. 1. Preoperative appearance showing a $2.0 \mathrm{~cm}$ sized, firm and protruding mass in the right orbital area.

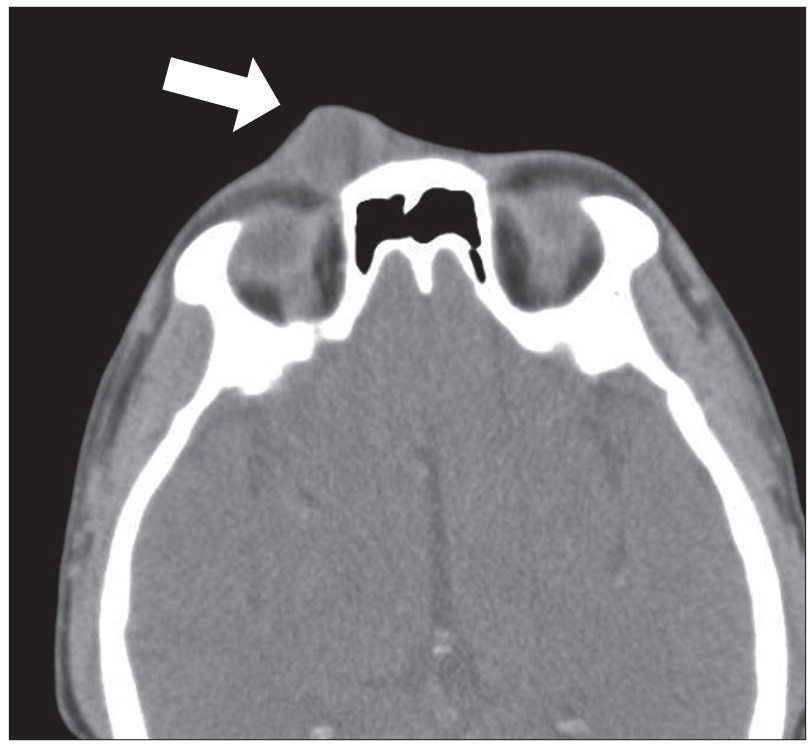

Fig. 2. Computed tomographic scan revealing an almost well-demarcated mass with a diameter of $2.0 \mathrm{~cm}$ on the orbital rim (white arrow). tained up to 1 year after excision and no recurrence was detected.

\section{DISCUSSION}

Nodular fasciitis was first described by Konwaler et al. [2] in 1955, and it has been referred to as pseudosarcomatous fasciitis, peudosarcomatous fibromatosis, proliferative fasciitis or infiltrative fasciitis. This disease occurs primarily in adults in the third and fourth decades of life, regardless of sex [4]. It can develop in any area but there is a prevalence of observed cases in the upper extremities and the trunk [5-7]. Only approximately $7 \%$ of nodular fasciitis are found on the head and neck areas and such cases generally occur in young children [5-9]. Nodular fasciitis is especially

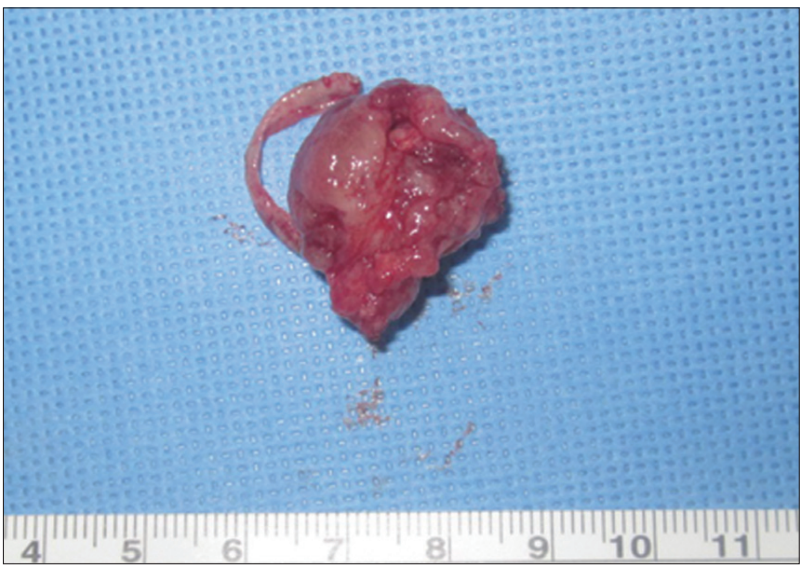

Fig. 3. Excised lesion showing a well demarcated soft tissue mass measuring $2.5 \times 2.0 \times 1.5 \mathrm{~cm}$ in size.

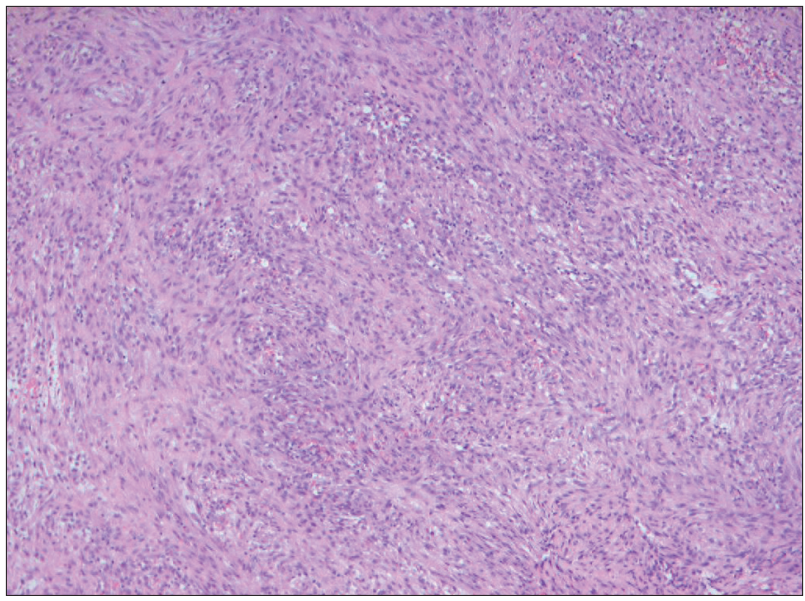

Fig. 4. Photomicrgraph showing randomly distributed fascicles of immature and uniform fibroblastic cells $(\mathrm{H} \& \mathrm{E}, \times 100)$. 


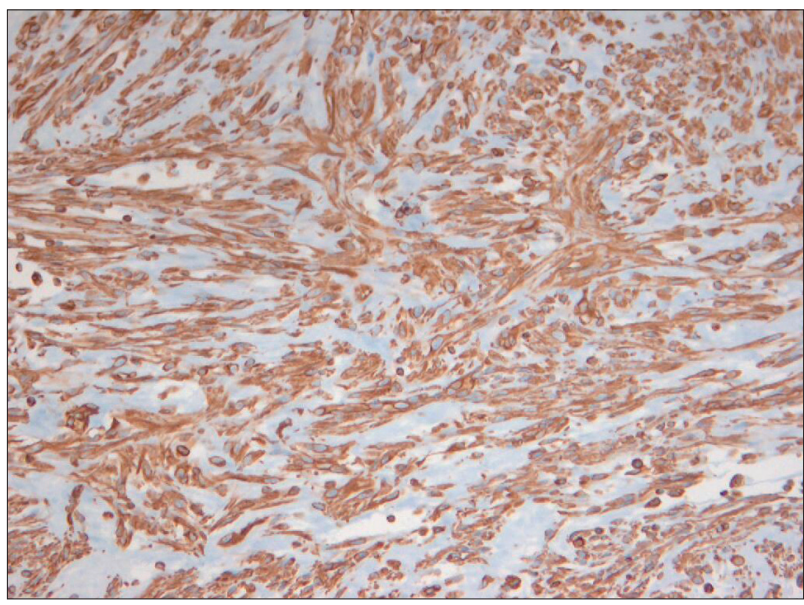

Fig. 5. Photomicrograph showing immunoreactivity of the spindle cells for vimentin $(\times 200)$.

uncommon in the periorbital area, only accounting for less than $1 \%$ of all periorbital masses [1]. The lesion ranges from 0.5 to 10.0 $\mathrm{cm}$ in size, with most being less than $4 \mathrm{~cm}$ with preclinical course of 4 weeks or less [10]. Although specific causes have not been reported, a history of trauma was found in approximately less than $1.5 \%$ of cases. In computed tomography or magnetic resonance imaging findings, the mass is well defined and homogeneous without invasion to adjacent tissues [11]. The histologic characteristics of nodular fasciitis include proliferation of spindle cell fibroblasts, frequently arranged in parallel bundles extending to all directions, and numerous mitoses of the spindle cell nuclei may also be seen [1]. The proliferation of capillary blood vessels and lymphocytic infiltration and extravasated red blood cells are also detected [4]. In immunohistochemical study, spindle-shaped fibroblasts in nodular fasciitis were shown to be positive for vimentin and sometimes actin but negative for keratin or S-100 protein [4].

Since the disease can be completely healed by a single surgical resection, the recommended treatment is complete conservative excision [5]. Following complete excision, local recurrence is reported to be rare [12]. Even in cases where complete resection could not be performed, it is usually resolved within a few months [13]. However, due to its rapid growth and the histopathologic similarity, nodular fasciitis could be misdiagnosed as a malignancy and an aggressive treatment may be inappropriately performed. Yoo et al. [4] have also previously reported that one must take caution of the possibility of such misdiagnosis, especially like in our

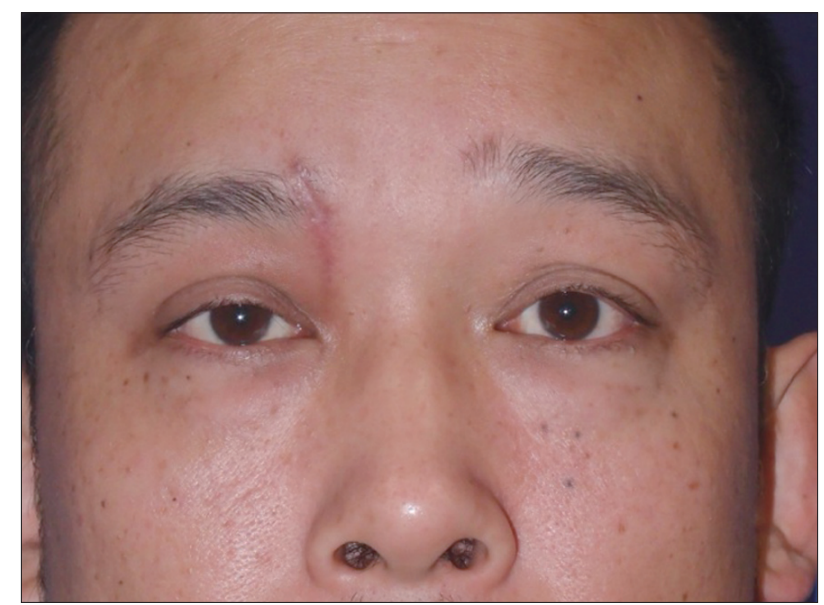

Fig. 6. Postoperative appearance, 3 weeks after excision.

case where a nodular fasciitis has occurred in an aesthetically prominent region such as the periortbital area. It is important that a treatment plan is established through an accurate diagnosis to avoid an unnecessarily aggressive treatment and to lead to an aesthetically favorable result. Also, according to Gelfand et al. [6] spontaneous regression can occur in some cases after incomplete excision; therefore it is possible to hold a surgical procedure and wait for regression under close observation. Other authors suggested steroid as a treatment option as well [14]. They published a case of nodular fasciitis on the arm that responded to intralesional steroid with complete resolution in 36 hours. Such method may act as an alternative treatment for nodular fasciitis in cases where a complete excision is difficult, and this treatment may also be applied to aesthetically important areas such as the head and neck.

In this article, we report a case of relatively uncommon periorbital nodular fasciitis that occurred in an adult. Although cases of fasciitis in the orbital area occur with lower than $1 \%$ probability, it is still important to suspect nodular fasciitis and to establish a proper treatment plan after an accurate diagnosis. Such careful steps will reduce unnecessary psychological morbidity and lead to aesthetically favorable results.

\section{REFERENCES}

1. Riffle JE, Prosser AH, Lee JR, Lynn JJ. Nodular fasciitis of the orbit: a case report and brief review of the literature. Case Rep Ophthalmol 
Med 2011;2011:235956.

2. Konwaler BE, Keasbey L, Kaplan L. Subcutaneous pseudosarcomatous fibromatosis (fasciitis). Am J Clin Pathol 1955;25:241-52.

3. Yanagisawa A, Okada H. Nodular fasciitis with degeneration and regression. J Craniofac Surg 2008;19:1167-70.

4. Yoo G, Baek SO, Jung SN, Kwon H, Moon SH, Shon WI. Nodular fasciitis in the forehead. JCraniofac Surg 2010;21:925-6.

5. Silva P, Bruce IA, Malik T, Homer J, BanerjeeS. Nodular fasciitis of the head and neck. J Laryngol Otol 2005;119:8-11.

6. Gelfand JM, Mirza N, Kantor J, Yu G, Reale D, Bondi E, JunkinsHopkins JM. Nodular fasciitis. Arch Dermatol 2001;137:719-21.

7. Thompson LD, Fanburg-Smith JC, Wenig BM. Nodular fasciitis of the external ear region: a clinicopathologic study of 50 cases. Ann Diagn Pathol 2001;5:191-8.

8. Katada T, Tsuchimochi M, Oda T, Sasaki Y, Toyama M, Katagiri M.
Magnetic resonance imaging findings of nodular fasciitis in the mental region. Odontology 2004;92:77-80.

9. Meffert JJ, Kennard CD, Davis TL, Quinn BD. Intradermal nodular fasciitis presenting as an eyelid mass. Int J Dermatol 1996;35:548-52.

10. Stanley MW, Skoog L, Tani EM, Horwitz CA. Nodular fasciitis: spontaneous resolution following diagnosis by fine-needle aspiration. Diagn Cytopathol 1993;9:322-4.

11. Meyer CA, Kransdorf MJ, Jelinek JS, Moser RP Jr. MR and CT appearance of nodular fasciitis. J Comput Assist Tomogr 1991;15:276-9.

12. Vestal KP, Bauer TW, Berlin AJ. Nodular fasciitis presenting as an eyelid mass. Ophthal Plast Reconstr Surg 1990;6:130-2.

13. Chartier S, Allaire G, Toscano M. Nodular fasciitis of the upper lip mimicking a sarcoma. Int J Dermatol 1994;33:503-4.

14. Graham BS, Barrett TL, Goltz RW. Nodular fasciitis: response to intralesional corticosteroids. J Am Acad Dermatol 1999;40:490-2. 